\title{
Baseline Exercise Tolerance and Perceived Dyspnea to Identify the Ideal Candidate to Pulmonary Rehabilitation: A Risk Chart in COPD Patients
}

This article was published in the following Dove Press journal: International Journal of Chronic Obstructive Pulmonary Disease

\author{
Stefania Costi (D) \\ Ernesto Crisafulli (iD ${ }^{2}$ \\ Ludovico Trianni ${ }^{3}$ \\ Bianca Beghè ${ }^{4}$ \\ Silvia Faverzani (iD) ${ }^{5}$ \\ Giuseppe Scopelliti $\mathbb{1 D}^{5}$ \\ Alfredo Chetta ${ }^{5}$ \\ Enrico Clini ${ }^{4}{ }^{4}$ \\ 'Department of Surgical, Medical and \\ Dental Department of Morphological \\ Sciences Related to Transplants Oncology \\ and Regenerative Medicine-University of \\ Modena and Reggio Emilia and Azienda \\ Unità Sanitaria Locale - IRCCS, Reggio \\ Emilia, Italy; ${ }^{2}$ Department of Medicine, \\ Respiratory Medicine Unit and Section of \\ Internal Medicine, University of Verona and \\ Azienda Ospedaliera Universitaria \\ Integrata of Verona, Verona, Italy; \\ ${ }^{3}$ Rehabilitation Unit-Hospital Villa Pineta, \\ Pavullo Nel Frignano, Modena, Italy; \\ ${ }^{4}$ Department of Medical and Surgical \\ Sciences-University of Modena and Reggio \\ Emilia and University Hospital of Modena \\ Policlinico, Modena, Italy; ${ }^{5}$ Department of \\ Medicine and Surgery, Respiratory Disease \\ and Lung Function Unit, University of \\ Parma, Parma, Italy
}

Background: The appropriate criteria for patient selection are still a key issue in the clinical management of patients referred to pulmonary rehabilitation (PR).

Methods: We retrospectively analyzed the records of a wide population of 1470 outpatient or inpatients with chronic obstructive pulmonary disease (COPD) referred to standard PR at two specialized Italian centers. Two models of multivariate logistic regression were developed to test the predictive powers of baseline exercise tolerance, namely the distance walked in 6 mins (6MWD), and of baseline dyspnea on exertion, measured by the modified Medical Research Council scale (mMRC), versus the minimal clinically important difference (MCID) for the same outcomes.

Results: Compared to the category of individuals with $6 \mathrm{MWD}>350$ meters, those patients with $201-350$ meters and $\leq 200$ meters showed a higher probability $(\mathrm{p}<0.001)$ of predicting a MCID change. Compared to the category of individuals with mMRC 0-1point, all the other categories $(2,3$, and 4$)$ also showed a higher probability $(\mathrm{p}<0.001)$ of predicting a MCID change. The incorporation of baseline categories of $6 \mathrm{MWD}$ and $\mathrm{mMRC}$ in a risk chart showed that the percentage of patients reaching MCID in both variables increased as the baseline level of 6MWD decreased and of mMRC increased.

Conclusion: This study demonstrates that lower levels of exercise tolerance and greater perceived dyspnea on exertion predict achieving clinically meaningful changes for both these treatment outcomes following PR. A specific risk chart that integrates these two variables may help clinicians to select ideal candidates and best responders to PR.

Keywords: chronic obstructive pulmonary disease, pulmonary rehabilitation, patient selection, minimal clinically important difference, exercise tolerance, dyspnea

\section{Introduction}

Pulmonary rehabilitation (PR) is a comprehensive and tailored intervention recommended to patients with chronic obstructive pulmonary disease (COPD). ${ }^{1}$ In the context of patient selection, PR provides benefits independently of baseline characteristics and others such as age, ${ }^{2}$ functional stages, ${ }^{3}$ comorbidities, ${ }^{4,5}$ and physical frailty. ${ }^{6}$ Even in cachectic COPD patients, a PR effect on physical capacity and on muscle remodeling has been proven. ${ }^{7}$

Although, at least theoretically, all COPD patients are potential candidates to PR based on the occurrence and persistence of symptoms and disability, it has been shown that different multidimensional profiles, ${ }^{8}$ disability level at baseline, ${ }^{5}$ and dyspnea perception may affect the response to PR and predict its likely effectiveness. ${ }^{9}$ Specific
Correspondence: Ernesto Crisafulli Department of Medicine, Respiratory Medicine Unit and Section of Interna Medicine, University of Verona and Azienda Ospedaliera Universitaria Integrata of Verona, Verona, Italy Email ernesto.crisafulli@univr.it 
determinants of PR success concerning the degree of breathlessness, body weight, or gas exchange have been thus identified. ${ }^{10}$ Walking limitation and perceived dyspnea, however, represent two common, easy-to-measure characteristics of disabled COPD patients. ${ }^{1}$

In clinical practice around the world, the main factors that impede the actual delivery of PR services to suitable patients ${ }^{11}$ are related to limited funding and reimbursement, lack of healthcare professionals and expertise, ${ }^{12}$ poor patient awareness, and/or additional patient-related barriers. ${ }^{11}$ Since $\mathrm{PR}$ is a challenging intervention for individuals and given the current need to allocate the available resources properly, referring clinicians should improve their ability to better screen eligible patients. This would help to identify those individuals that would benefit most from PR.

Accordingly, we investigated the predictive role of both the baseline distance walked (6MWD) and the mMRC (Modified Medical Research Council) Dyspnea Scale score on successful PR, as defined by clinically meaningful changes in these two relevant measurements. Thus, in a population of COPD patients with different categories of baseline disability referring to these two outcome measures, we tested the probability of achieving the minimal clinically important difference (MCID) for both these patient-centered outcomes following PR.

\section{Methods}

\section{Study Sample}

This retrospective study analyzed stable COPD patients admitted to a pulmonary rehabilitation program. The institutional review board and ethical committee of each hospital approved the study, conducted according to the Declaration of Helsinki. Patient data were treated confidentially and patients' consent to review their medical records was not required.

Patients were cared for by the Rehabilitation Unit of Villa Pineta Hospital (Pavullo n/F (MO), Italy) from 2002 to 2010 ( $\mathrm{n}=1394)$ or by the Respiratory Disease and Lung Function Unit (Parma, Italy) from 2016 to $2018(\mathrm{n}=76)$. The primary diagnosis of COPD was defined according to the Global Initiative for Chronic Obstructive Lung Disease criteria. ${ }^{13}$ We excluded COPD patients: a) with an acute event in the 4 weeks prior to enrollment; b) with a coexisting diagnosis of asthma or any other pulmonary disease; c) with any comorbidity affecting exercise performance (anemia, disabling neuromuscular conditions, acute cardiac failure, malignancies); d) with cognitive impairments that might have interfered with the adherence to the rehabilitation program; e) who withdrew from the PR for any cause or patients in whom it was not possible to obtain the measures of exercise tolerance or dyspnea perception at discharge. Data on all patients were analyzed and reported anonymously. No extramural funding was used to support the study.

\section{General Measurements}

Age, sex, and body mass index-BMI were recorded at enrolment. Lung function was measured at baseline by means of standard spirometry, performed according to international recommendations. ${ }^{14}$ Arterial blood samples were taken for gas analysis. Concomitant chronic diseases were assessed by the self-reported Charlson Comorbidity Index, which assigns to each disease a score that is proportional to the related risk of death. ${ }^{15}$ The self-reported prevalence of some chronic diseases (arterial hypertension, diabetes, coronary disease, chronic heart failure, dyslipidemia, and osteoporosis) was collected.

\section{Rehabilitation Program and Outcomes}

Patients included were treated on an inpatient or outpatient basis, depending on the individual's level of functional limitations, and the patient's preference. The rehabilitation program consisted of 21 consecutive $3 \mathrm{hr}$ sessions and included in each session standard activities (peripheral limb training, respiratory muscle training, chest physiotherapy), and psychological and nutritional counselling when indicated. The program was conducted in the same way at the two facilities, as previously reported. ${ }^{4}$ Physiotherapists involved were previously instructed to homogenize the type and duration of all activities. $^{4}$

The outcomes were analyzed as pre-to-post PR change in exercise tolerance by the $6 \mathrm{~min}$ walking distance test (6MWD) and perceived dyspnea on exertion by the modified Medical Research Council Dyspnea Scale (mMRC). The 6MWD was performed according to the international recommendations, ${ }^{16}$ and repeated twice to limit the leaning effect; the best distance was recorded. The daily living activities-related dyspnea was evaluated with the Italian version of the MRC modified by the American Thoracic Society. ${ }^{17}$

\section{Statistical Analysis}

Categorical variables are reported as number or percentage, whereas continuous variables are indicated as medians 
(interquartile range) due to a non-normal distribution and are then compared using the non-parametric Mann-Whitney test.

Two models of multivariate logistic regression were developed to test the predictive power of baseline 6MWD and $\mathrm{mMRC}$ score versus the relative predefined post-PR change (i.e. the minimal clinically important differenceMCID) in both walking capacity (6MWD $\geq 30$ meters) ${ }^{18}$ and dyspnea score (mMRC -1 point) ${ }^{19}$ (as the dependent variables).

In the first model, we used baseline values of 6MWD and $\mathrm{mMRC}$ as continuous variables. To explore the role of these variables as outcomes, we retrieved the predicted probability of reaching the MCID in both 6MWD and mMRC for each patient from the final model and plotted it against the respective absolute baseline values. In the second model, we used categorical variables of baseline 6MWD ( $\leq 200$ meters, 201-350 meters, $>350$ meters) and $\mathrm{mMRC}(0-1$ points, 2 points, 3 points, 4 points). The choice of these categories was based on the possibility of distinguishing between patients with less impairment and fewer symptoms (6MWD >350 meters and mMRC 0-1 points) and those who are more compromised (6MWD $\leq 200$ meters and mMRC 4 points). The value limits of the three $6 \mathrm{MWD}$ categories refer to the greatest, average, or least performance ${ }^{20}$ and to the prognostic indication of each in terms of mortality risk, ${ }^{21-23}$ as previously reported in the literature. Both models were adjusted for age, sex, comorbidities (Charlson index $\geq$ the median value of 2 ), severity of airflow obstruction (forced expiratory volume at 1 st second $-\mathrm{FEV}_{1} \leq 50 \%$ pred.), and clinical setting (outpatient/inpatient). We then calculated the odds ratios (ORs) and 95\% confidence intervals (CI), and the calibration ability with the Hosmer-Lemeshow goodness-of-fit test.

All analyses were performed using IBM SPSS, version 25.0 (IBM Corp., Armonk, NY, USA). A p-value of $<0.05$ was considered statistically significant.

\section{Results}

Our study cohort considered 1470 symptomatic COPD patients who were elderly males with a moderate to severe airflow obstruction, moderate number of comorbidities (principally arterial hypertension), moderate walking ability and dyspnea perception. Data on body weight and gas exchange were reported and then collected from a small proportion of individuals (13\% and 19\%, respectively). Chronic respiratory failure was present in $17 \%$ of the total sample. General characteristics of our study sample are reported in Table 1.

Figure 1 illustrates the linear regression analyses exploring the predictive power of continuous baseline 6MWD and mMRC versus each respective MCID. The risk of reaching the MCID increased for the 6MWD and for the $\mathrm{mMRC}$ score in patients with a lower walking capacity [odds ratio-OR 0.995 (95\% confidence intervalCI 0.993-0.998)] and a higher dyspnea level [OR 4.52 (95\% CI 3.35-6.10)], respectively.

Figure 2 shows the significant distribution of pre-topost change in 6MWD (left panel) and mMRC (right panel) according to the baseline categories. Patients with a worse walking distance $(6 \mathrm{WMD} \leq 200$ meters) and perceived dyspnea (mMRC 3-4 points) had greater improvement post-rehabilitation $(\mathrm{p}<0.001$ between each category considered).

Table 2 reports the multivariate regression analyses that explored the probability of achieving the MCID in both 6MWD and mMRC, based on their baseline categorical variables. Compared to the category of individuals walking $>350$ meters, the categories of both those performing 201-350 meters [OR 1.9 (95\% CI 1.2-2.8)] and those performing $\leq 200$ meters [OR 1.5 (95\% CI 0.86-2.8)]

Table I General Characteristics of Study Cohort $(n=1470)$

\begin{tabular}{|l|l|l|}
\hline Variables & $\mathbf{n}$ & Value \\
\hline $\mathrm{Age}$, years & 1463 & $7 \mathrm{I}[\mathrm{I0}]$ \\
$\mathrm{Male}, \%$ & 1470 & 75 \\
$\mathrm{BMI}, \mathrm{kg} / \mathrm{m}^{2}$ & 185 & $26.7[5.5]$ \\
$\mathrm{FEV}_{1}, \% \mathrm{pred}$. & 1443 & $50[23]$ \\
$\mathrm{PaO}_{2}, \mathrm{mmHg}$ & 273 & $70[12.9]$ \\
$\mathrm{PaCO}_{2}, \mathrm{mmHg}$ & 274 & $40.9[6.7]$ \\
$\mathrm{Chronic}$ respiratory failure, \% & 1470 & 17 \\
Charlson index & 1135 & $2[1]$ \\
$\mathrm{Hypertension,} \mathrm{\%}$ & 1277 & 30 \\
Diabetes, \% & 1277 & $1 \mathrm{I}$ \\
Coronary disease, \% & 1277 & 8 \\
Chronic heart failure, \% & 1277 & 10 \\
Dyslipidemia, \% & 1277 & 9 \\
Osteoporosis, \% & 1277 & 5 \\
6MWD, baseline & 1467 & $360[120]$ \\
mMRC, baseline & 1174 & $2[1]$ \\
SGRQ, baseline & 569 & $40[23]$ \\
Outpatients/lnpatients, \% & 1470 & $45 / 55$ \\
\hline
\end{tabular}

Notes: Data are shown as number of patients (\%) or medians [interquartile range]. Percentages are calculated on non-missing data.

Abbreviations: $\mathrm{BMI}$, body mass index; $\mathrm{FEV}_{1}$, forced expiratory volume at $1^{\text {st }}$ second; $\mathrm{PaO}_{2}$, partial arterial oxygen pressure; $\mathrm{PaCO}_{2}$, partial arterial carbon dioxide pressure; 6MWD, six-minute walking distance; mMRC, modified Medical Research Council Dyspnea Scale; SGRQ, St. George's Respiratory Questionnaire. 

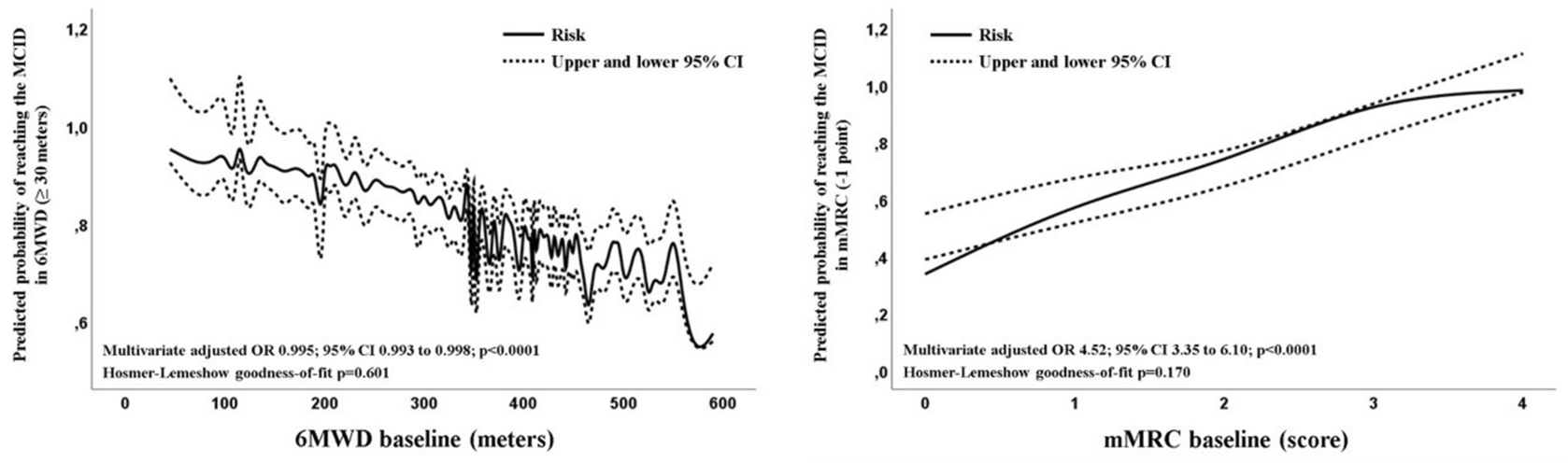

Figure I Multivariate adjusted linear regression model predicting the probability of reaching the MCID in 6MWD and mMRC.
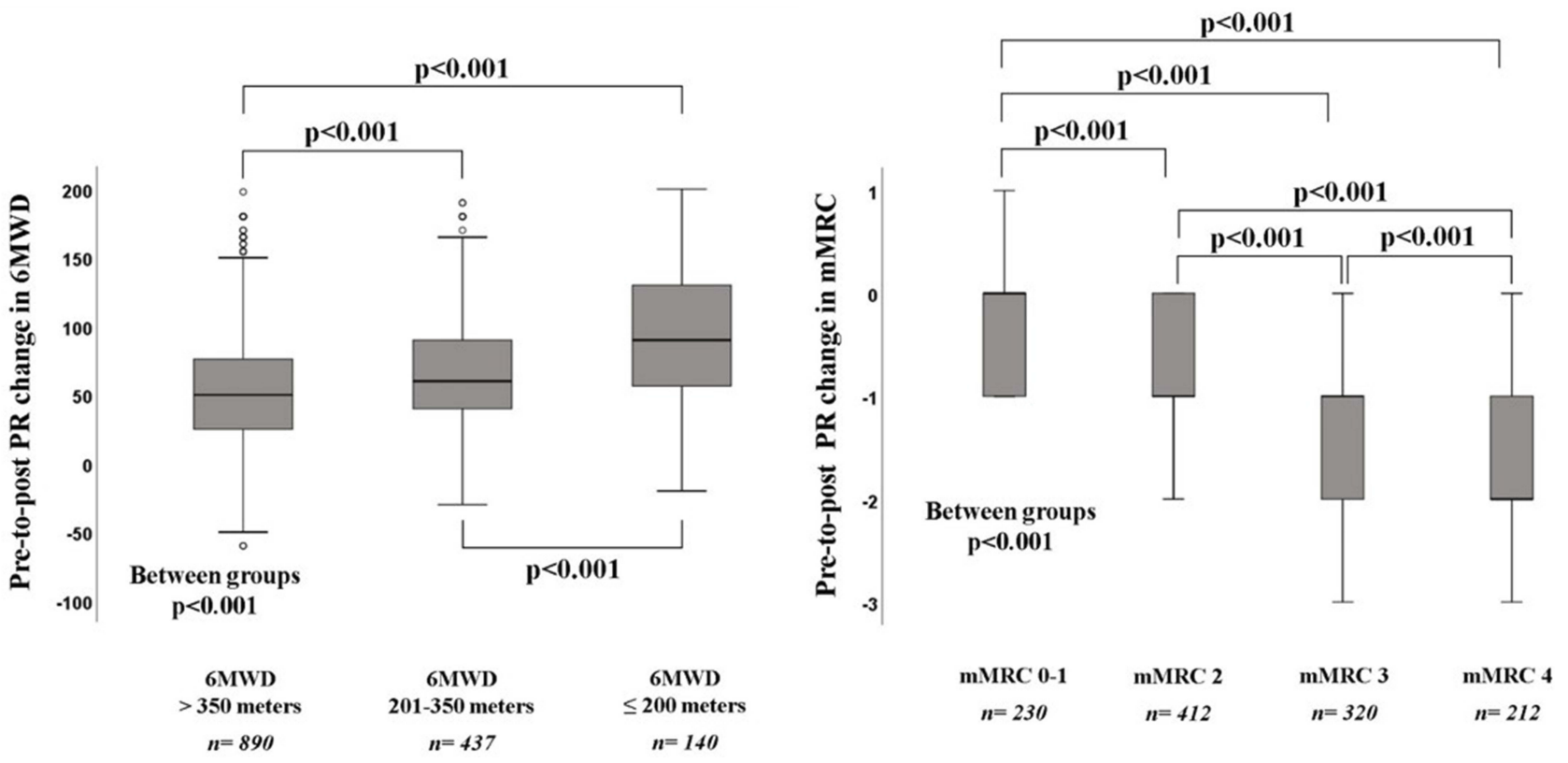

Figure 2 Distribution of pre-to-post PR changes in 6MWD and mMRC, according to the baseline categories.

showed a higher probability of predicting the achievement of the MCID for 6MWD, although the latter category was not statistically significant $(\mathrm{p}=0.141)$. Similarly, compared to the category of individuals with lower dyspnea on exertion $(0-1$ point at $\mathrm{mMRC})$, the other 3 categories, representing progressively increasing levels of breathlessness, showed a higher probability of predicting the achievement of the MCID for the mMRC.

The incorporation of baseline categories of 6MWD and mMRC with the percentage of patients reaching the MCID in both outcomes (6MWD $\geq 30$ meters and mMRC -1 point) into a risk chart is reported in Figure 3. This chart shows that few patients reached the MCID for both outcomes $(0-30 \%$, red box $)$ if they had higher baseline exercise tolerance (6MWD $>350$ meters) and lower baseline dyspnea perception (mMRC $0-1$ ), while the percentage of patients progressively increased (yellow and green boxes) according to the increase in mMRC categories and the decrease in baseline 6MWD.

\section{Discussion}

This retrospective study on a large cohort of COPD patients admitted to a PR program provides two important conclusions. First, it demonstrates that patients' baseline assessment in terms of both the distance walked (6MWD) and their perceived dyspnea on exertion (mMRC) predicts post-rehabilitation clinically meaningful changes. Second, the risk chart integrating specific categories of these two baseline measures identifies those patients who have greater or lesser benefit from participating in PR, thus 
Table 2 Multivariate Regression Analyses Predicting the Probability of Reaching the MCID in Exercise Tolerance and Dyspnea Perception

\begin{tabular}{|c|c|c|c|}
\hline & \multicolumn{3}{|c|}{ Multivariate Adjusted* } \\
\hline & OR & $95 \% \mathrm{Cl}$ & p-value \\
\hline \multicolumn{4}{|l|}{$\begin{array}{l}\text { Dependent variable: MCID in } \\
6 \mathrm{MWD} \text { ( } \geq 30 \text { meters) }\end{array}$} \\
\hline \\
\hline Patients with baseline 6MWD & I & - & - \\
\hline \multicolumn{4}{|l|}{$>350$ meters $(n=890)$} \\
\hline Patients with baseline 6MWD & 1.9 & $1.2-2.8$ & 0.003 \\
\hline between $20 \mathrm{I}-350$ meters $(n=437)$ & & & \\
\hline Patients with baseline 6MWD & 1.5 & $0.86-2.8$ & 0.141 \\
\hline \multicolumn{4}{|l|}{$\leq 200$ meters $(n=\mid 40)$} \\
\hline \multicolumn{4}{|l|}{$\begin{array}{l}\text { Dependent variable: MCID in } \\
\text { mMRC ( }- \text { I point) }\end{array}$} \\
\hline $\begin{array}{l}\text { Patients with baseline mMRC } 0-I \\
\text { points }(n=230)\end{array}$ & 1 & - & - \\
\hline $\begin{array}{l}\text { Patients with baseline mMRC } 2 \\
\text { points }(n=4 \mid 2)\end{array}$ & 4.3 & $2.3-7.7$ & $<0.001$ \\
\hline $\begin{array}{l}\text { Patients with baseline mMRC } 3 \\
\text { points }(n=320)\end{array}$ & 17.8 & $8.5-38.5$ & $<0.001$ \\
\hline $\begin{array}{l}\text { Patients with baseline mMRC } 4 \\
\text { points }(n=2 \mid 2)\end{array}$ & 29.7 & I2.2-72.4 & $<0.001$ \\
\hline
\end{tabular}

Notes: *Adjusted for anthropometric characteristics, comorbidities, severity of airflow obstruction, and setting. Hosmer-Lemeshow goodness-of-fit $p=0.744$ and $\mathrm{p}=0.936$ for models with dependent variable the MCID of 6MWD and mMRC, respectively. Bold data indicate statistical significance.

clarifying who is the best candidate in the selection of patients.

To date, there is much evidence proving the efficacy of a standard PR course in symptomatic COPD patients, ${ }^{1,18,24}$ even in those complex individuals who were previously excluded from programs due to their physical frailty, ${ }^{6}$ degree of comorbidities, ${ }^{5}$ or cachexia. ${ }^{7}$ Therefore, we now know that these complex patients ${ }^{2,3,5-7}$ should not be excluded a priori from rehabilitation.

Predictors of improvement following PR might be seen on admission and include either degree of breathlessness, body weight, or gas exchange (i.e. arterial partial pressure of oxygen); ${ }^{10}$ however, gains and benefits in patients treated with PR are not predictable by other usual measures such as sleep quality, social behaviors, and so on. ${ }^{10}$

To the best of our knowledge, this study is the first to adopt an aimed and pre-specified hypothesis to explore the role of two relevant and easy-to-collect outcome variables (6MWD and mMRC) as predictors of improvement up to MCID following a standard PR course.

At baseline, it is very likely that both of these two outcome measures describe important characteristics of symptomatic

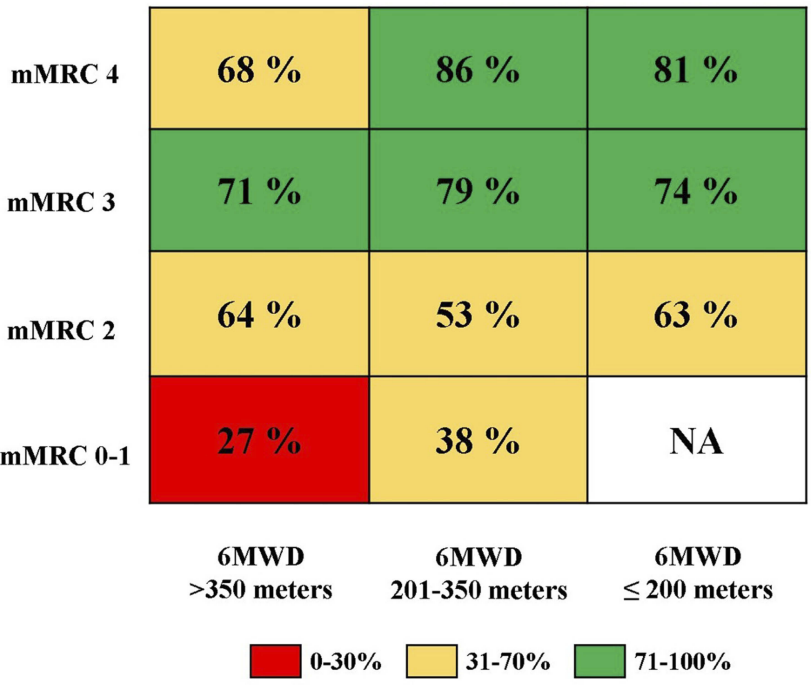

Figure 3 Risk chart integrating baseline categories of exercise tolerance and of dyspnea perception, with the percentage of patients reaching the MCID in both outcomes (6MWD $\geq 30$ meters and $m M R C-I$ point).

Abbreviation: NA, indicates not applicable.

COPD candidates to PR. ${ }^{25,26}$ It is noteworthy that, a previous prospective observational study of over 300 complex comorbid COPD patients ${ }^{5}$ showed the predictive role of baseline 6MWD and mMRC score on the efficacy of outpatient PR, compared to other outcomes. Nevertheless, the present analysis presents major differences compared to the study by Crisafulli et al, ${ }^{5}$ namely 1 ) a stronger methodology to test the hypothesis, with two regression models exploring continuous and dichotomous variables of the outcomes considered (see Figure 1 and Table 2); 2) a large study cohort including more than 1400 candidates; 3) the assessment and analysis of patients referred to either outpatient or inpatient PR settings; 4) the adoption of updated criteria for the MCID in 6MWD (i.e. +30 meters), different from that previously defined by Redelmeier et al; ${ }^{27} 5$ ) a multiple adjustment of the regression models, which considered several variables connoting patient's complexity and lung impairment, thus extending its validity to the typical patients referred to a PR program in real life.

Our choice to categorize COPD patients by threshold limits of $6 \mathrm{MWD}$, although perhaps apparently arbitrary, was in fact based on the previous literature ${ }^{20-23}$ and related to the patients' different performance and prognosis. As for the wellknown clinical and prognostic value of the different categories of the $\mathrm{mMRC}^{17}$ that we also used in this study, we think that the categories here proposed for the 6MWD represent different levels of disability and might play a prognostic role similar to that of mMRC in accurately predicting a meaningful gain post-PR (Figure 2). 
Since the response to PR may vary considerably among COPD patients, ${ }^{10,28}$ as long as available resources are still limited, ${ }^{11,12}$ it seems appropriate to implement a careful selection process of all potential candidates once they are referred to PR. ${ }^{1,11}$ Notwithstanding a global call to implement and expand the referral to PR worldwide, ${ }^{29}$ the selection process should inform the appropriate indication at the individual level, something that remains a cornerstone in this clinical field.

Our attempt to create an easy-to-interpret risk chart that incorporates the measures of exercise tolerance and of dyspnea perception on exertion (Figure 3) responds to the actual need to identify the good responder to PR (namely, the best candidate). Findings obtained with this tool are in line with those reported very recently, which show that different responses to PR in the COPD population substantially depend on patients' baseline profile, as defined by a multidimensional assessment. ${ }^{8}$ In our study, very good responders to PR were indeed those individuals showing higher dyspnea and worse exercise tolerance at baseline. ${ }^{8}$ Clearly, the identification of the best candidate in our risk chart is based on these two outcomes. Nonetheless, we cannot exclude that COPD patients may also improve according to other outcome measures (i.e. health status or health-related quality of life). ${ }^{1,10}$

Although COPD patients may show differential responses to PR when considering different outcome measures, ${ }^{19}$ the chance to incorporate multiple patient domains into a single response to $\mathrm{PR}^{8}$ still remains controversial and/or might be difficult to apply in different contexts and organizations worldwide. ${ }^{30}$ Although the approach of a cluster analysis based on the patient's multidimensional response to PR represents a novel and intriguing opportunity for clinicians, ${ }^{8}$ it does not substitute the need for a very simple criterion for users. For example, although cycle endurance time through a constant workrate test may predict response to $\mathrm{PR}$ in terms of exercise tolerance, thus discriminating different categories of response, skills and technologies might be not accessible worldwide. In addition, there might also be other measures that, at baseline, are not predictors per se. ${ }^{8}$ Therefore, in future, global perspective to implementing $\mathrm{PR}$ and to selecting ideal candidates, 6MWD and mMRC are still identifiable as key outcomes. ${ }^{30}$ Indeed, our risk chart starts from both the easy-to-use and the easy-to-interpret concepts.

The strengths of this retrospective study are the large cohort of patients included, the strong methodology based on two different adjusted models of regression analysis, and the original proposal of a chart to implement in the selection process of candidates to PR. This latter might be translated into a simple, practical message to help physicians to prioritize resources, at least within the COPD population.

Despite this, we here recognize some important limitations that readers should also consider. First, the analysis was based on retrospective data; our results need to be confirmed prospectively. Second, we had limited access to data on other outcomes (e.g. perceived health-related quality of life) as well as on other COPD-related factors such as smoking status, long-term oxygen therapy, fat-free mass index, physical activity level, and exacerbation rates, which could not thus be integrated into the chart. Finally, our analyses were done on a prevalence of males and therefore need to be confirmed in a sample with more females.

In conclusion, our study demonstrates that the baseline levels of exercise tolerance and dyspnea on exertion, as measured by two simple and accessible outcomes (6MWD and mMRC) predict the COPD patient's response to PR. A risk chart incorporating these two variables may easily identify any ideal candidate and best responder to a standard PR course.

\section{Acknowledgments}

We thank Jacqueline M. Costa for the English language editing.

\section{Disclosure}

The authors declare that there is no conflict of interest regarding the publication of this paper.

\section{References}

1. Spruit MA, Singh SJ, Garvey C, et al. ATS/ERS task force on pulmonary rehabilitation. An official American Thoracic Society/ European Respiratory Society statement: key concepts and advances in pulmonary rehabilitation. Am J Respir Crit Care Med. 2013;188(8): e13-e64. doi:10.1164/rccm.201309-1634ST

2. Baltzan MA, Kamel H, Alter A, Rotaple M, Wolkove N. Pulmonary rehabilitation improves functional capacity in patients 80 years of age or older. Can Respir J. 2004;11:407-413. doi:10.1155/2004/632153

3. Vogiatzis I, Terzis G, Stratakos G, et al. Effect of pulmonary rehabilitation on peripheral muscle fiber remodeling in patients with COPD in GOLD stages II to IV. Chest. 2011;140:744-752. doi:10.1378/ chest.10-3058

4. Crisafulli E, Costi S, Luppi F, et al. Role of comorbidities in a cohort of patients with COPD undergoing pulmonary rehabilitation. Thorax. 2008;63(6):487-492. doi:10.1136/thx.2007.086371 
5. Crisafulli E, Gorgone P, Vagaggini B, et al. Efficacy of standard rehabilitation in COPD outpatients with comorbidities. Eur Respir J. 2010;36(5):1042-1048. doi:10.1183/09031936.00203809

6. Maddocks M, Kon SS, Canavan JL, et al. Physical frailty and pulmonary rehabilitation in COPD: a prospective cohort study. Thorax. 2016;71(11):988-995. doi:10.1136/thoraxjnl-2016-208460

7. Vogiatzis I, Simoes DC, Stratakos G, et al. Effect of pulmonary rehabilitation on muscle remodelling in cachectic patients with COPD. Eur Respir J. 2010;36:301-310. doi:10.1183/09031936.00112909

8. Spruit MA, Augustin IM, Vanfleteren LE, et al.; CIRO+ Rehabilitation Network. Differential response to pulmonary rehabilitation in COPD: multidimensional profiling. Eur Respir J. 2015;46 (6):1625-1635. doi:10.1183/13993003.00350-2015

9. Rugbjerg M, Iepsen UW, Jørgensen KJ, Lange P. Effectiveness of pulmonary rehabilitation in COPD with mild symptoms: a systematic review with meta-analyses. Int $J$ Chron Obstruct Pulmon Dis. 2015;10:791-801. doi:10.2147/COPD

10. Garrod R, Malerba M, Crisafulli E. Determinants of success. Eur Respir J. 2011;38(5):1215-1218. doi:10.1183/09031936.00088611

11. Rochester CL, Vogiatzis I, Holland AE, et al.; ATS/ERS Task Force on Policy In Pulmonary Rehabilitation. An official American Thoracic Society/European Respiratory Society policy statement: enhancing implementation, use, and delivery of pulmonary rehabilitation. $A m$ $J$ Respir Crit Care Med. 2015;192(11):1373-1386. doi:10.1164/ rccm.201510-1966ST

12. Keating A, Lee AL, Holland AE. Lack of perceived benefit and inadequate transport influence uptake and completion of pulmonary rehabilitation in people with chronic obstructive pulmonary disease: a qualitative study. J Physiother. 2011;57(3):183-190. doi:10.1016/ S1836-9553(11)70040-6

13. Global Strategy for the Diagnosis, Management and Prevention of COPD, Global Initiative for Chronic Obstructive Lung Disease (GOLD); 2018. Available from: http://goldcopd.org. Accessed December 18, 2019.

14. Miller MR, Hankinson J, Brusasco V, et al.; ATS/ERS Task Force. Standardisation of spirometry. Eur Respir J. 2005;26(2):319-338. doi:10.1183/09031936.05.00034805

15. Charlson ME, Pompei P, Ales KL, MacKenzie CR. A new method of classifying prognostic comorbidity in longitudinal studies: development and validation. $J$ Chronic Dis. 1987;40(5):373-383. doi:10.1016/0021-9681(87)90171-8

16. Holland AE, Spruit MA, Troosters T, et al. An official European Respiratory Society/American Thoracic Society technical standard: field walking tests in chronic respiratory disease. Eur Respir J. 2014;44(6):1428-1446. doi:10.1183/09031936.00150314

17. Fletcher CM. Standardised questionnaire on respiratory symptoms: a statement prepared and approved by the MRC Committee on the aetiology of Chronic Bronchitis (MRC breathlessness score). Br Med J. 1960;2:1665.
18. Puhan MA, Gimeno-Santos E, Cates CJ, Troosters T. Pulmonary rehabilitation following exacerbations of chronic obstructive pulmonary disease. Cochrane Database Syst Rev. 2016;12:CD005305.

19. de Torres JP, Pinto-Plata V, Ingenito E, et al. Power of outcome measurements to detect clinically significant changes in pulmonary rehabilitation of patients with COPD. Chest. 2002;121(4):1092-1098. doi:10.1378/chest.121.4.1092

20. Szekely LA, Oelberg DA, Wright C, et al. Preoperative predictors of operative morbidity and mortality in COPD patients undergoing bilateral lung volume reduction surgery. Chest. 1997;111 (3):550-558. doi:10.1378/chest.111.3.550

21. Casanova C, Cote C, Marin JM, et al. Distance and oxygen desaturation during the 6-min walk test as predictors of long-term mortality in patients with COPD. Chest. 2008;134(4):746-752. doi:10.1378/ chest.08-0520

22. Spruit MA, Polkey MI, Celli B, et al.; Evaluation of COPD Longitudinally to Identify Predictive Surrogate Endpoints (ECLIPSE) study investigators. Predicting outcomes from 6-minute walk distance in chronic obstructive pulmonary disease. $\mathrm{J} \mathrm{Am} \mathrm{Med}$ Dir Assoc. 2012;13(3):291-297. doi:10.1016/j.jamda.2011.06.009

23. Celli B, Tetzlaff K, Criner G, et al.; COPD Biomarker Qualification Consortium. The 6-minute-walk distance test as a chronic obstructive pulmonary disease stratification tool. Insights from the COPD biomarker qualification consortium. Am J Respir Crit Care Med. 2016;194(12):1483-1493. doi:10.1164/rccm.201508-1653OC

24. Clini EM, Crisafulli E, Costi S, et al. Effects of early inpatient rehabilitation after acute exacerbation of COPD. Respir Med. 2009;103(10):1526-1531. doi:10.1016/j.rmed.2009.04.011

25. Crisafulli E, Clini EM. Measures of dyspnea in pulmonary rehabilitation. Multidiscip Respir Med. 2010;5(3):202-210. doi:10.1186/2049-6958-5-3-202

26. Clini EM, Crisafulli E. Exercise capacity as a pulmonary rehabilitation outcome. Respiration. 2009;77(2):121-128. doi:10.1159/000192773

27. Redelmeier DA, Bayoumi AM, Goldstein RS, Guyatt GH. Interpreting small differences in functional status: the six minute walk test in chronic lung disease patients. Am J Respir Crit Care Med. 1997;155(4):1278-1282. doi:10.1164/ajrccm.155.4.9105067

28. Troosters T, Gosselink R, Decramer M. Exercise training in COPD: how to distinguish responders from nonresponders. J Cardiopulm Rehabil. 2001;21(1):10-17. doi:10.1097/00008483-200101000-00004

29. Nici L, Singh S, Holland AE, ZuWallack RL. Opportunities and challenges to expanding pulmonary rehabilitation into the home and community. Am J Respir Crit Care Med. In press 2019;200:822-827. doi:10.1164/rccm.201903-0548PP

30. Spruit MA, Pitta F, Garvey C, et al. ERS rehabilitation and chronic care, and physiotherapists scientific groups; American Association of Cardiovascular and Pulmonary Rehabilitation; ATS pulmonary rehabilitation assembly and the ERS COPD audit team. Differences in content and organisational aspects of pulmonary rehabilitation programmes. Eur Respir J. 2014;43(5):1326-1337. doi:10.1183/09031936.00145613

\section{Publish your work in this journal}

The International Journal of COPD is an international, peer-reviewed journal of therapeutics and pharmacology focusing on concise rapid reporting of clinical studies and reviews in COPD. Special focus is given to the pathophysiological processes underlying the disease, intervention programs, patient focused education, and self management protocols. This journal is indexed on PubMed Central, MedLine and CAS. The manuscript management system is completely online and includes a very quick and fair peer-review system, which is all easy to use. Visit http://www.dovepress.com/testimonials.php to read real quotes from published authors. 